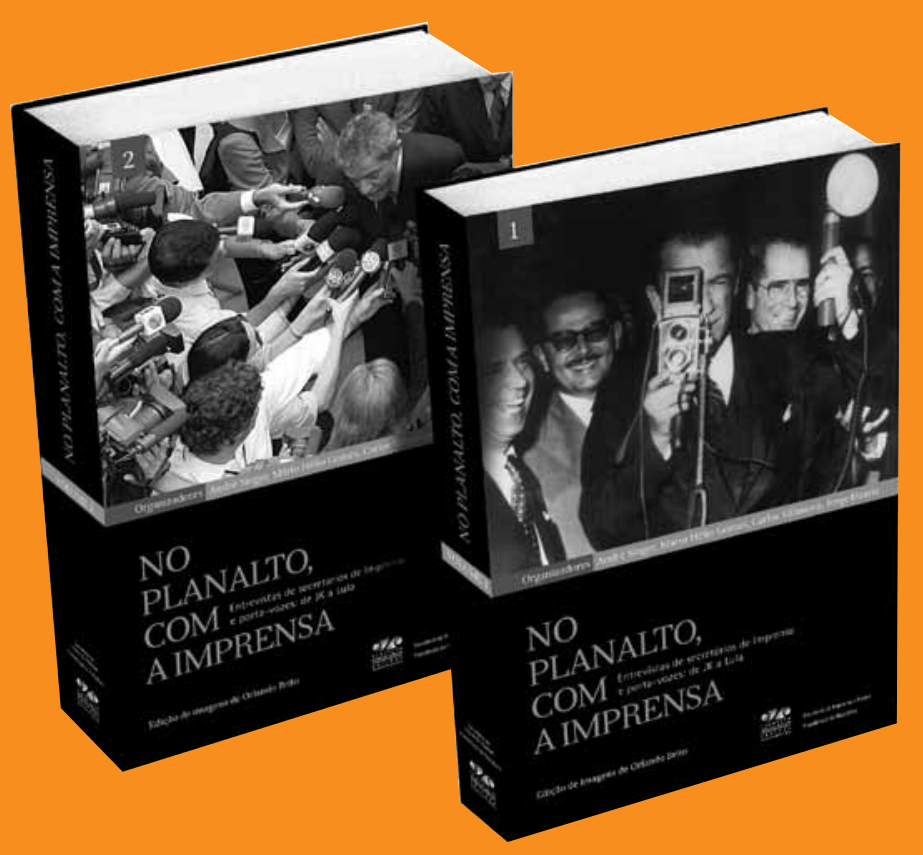

No Planalto, com a imprensa:

entrevistas de secretários de imprensa e porta-vozes - de JK a Lula

André Singer, Mário Hélio Gomes, Carlos Villanova, Jorge Duarte (Org.)

Brasília, DF; Recife, PE:

Secretaria de Imprensa da Presidência da República;

Editora Massangana - Fundação Joaquim Nabuco, 2010

Tomo I - 412 p.; Tomo II - 578 p.

Resenhado por:

João José Forni

- Mestre em Comunicação pela Universidade de Brasília (UnB)

- MBA em Gestão Estratégica, pela Universidade de São Paulo (USP)

- Graduado em Jornalismo pelo Centro Universitário de Brasília (UniCeub)

- Graduado em Letras pela Universidade Católica de Pelotas (UCP)

- Especialista em Gestão de Crises e Comunicação

- Editor do site www.comunicacaoecrise.com

-jforni@terra.com.br 


\section{Bastidores do Planalto: os homens dos presidentes e a relação com a imprensa}

In the wings of the Planalto Palace:

the presidents' men and the relationships with the press

\section{Bastidores del Planalto: los hombres de los presidentes y la relación con la prensa}

e dependesse da opinião dos secretários de imprensa dos presidentes da República nos últimos sessenta anos, o Brasil seria um país privilegiado. Todos os presidentes, de Juscelino Kubitschek até Lula, foram muito bons. Estadistas, inteligentes, tinham uma compreensão muito profunda do papel da imprensa. Quase todos se queixavam da imprensa: notícias boas seriam desprezadas, com ênfase nos erros, nas críticas e nos fatos negativos. Esta é uma das conclusões, após a leitura de No Planalto, com a imprensa: entrevistas de secretários de imprensa e porta-vozes - de JK a Lula, transcrição de entrevistas com 24 ex-secretários de imprensa e porta-vozes da Presidência da República.

A edição de quase mil páginas foi produzida pela Secretaria de Imprensa e Divulgação da Presidência da República, em parceria com a Fundação Joaquim Nabuco. Organizada por André Singer, Mário Hélio Gomes, Carlos Villanova e Jorge Duarte, conta também com um apêndice de fotos históricas do fotógrafo Orlando Brito. O projeto de reunir entrevistas com os secretários de imprensa começou em 2006, quando o então porta-voz da presidência, cientista político e professor André Singer, ao reformular a estrutura de comunicação, constatou não haver registro da passagem dos secretários de imprensa ou porta-vozes pela presidência. A maioria das entrevistas foi feita pelo jornalista e professor Jorge Duarte, em 2006. O material bruto rendeu cerca de quatro mil páginas, condensado para 987 em dois volumes, com excelente encadernação.

Os organizadores selecionaram 32 ocupantes do cargo de secretários e porta-vozes, do governo JK até 2006. Oito faleceram. Dos 26 que poderiam ter participado do projeto, dois não aceitaram o convite: José Maria de Toledo Camargo, secretário no governo Geisel, em 1977 e 1978; e a jornalista Ana Tavares, assessora de Imprensa de Fernando H. Cardoso durante oito anos. Isso 
não diminuiu a importância da edição e nem enfraqueceu o excelente material histórico resultante das entrevistas.

A edição contém 295 notas de rodapé, com uma breve biografia de pessoas citadas nas entrevistas, principalmente políticos e jornalistas, ou explicação sobre instituições ou fatos históricos, que ajudam na contextualização histórica e compreensão dos depoimentos. Contém também uma introdução de Jorge Duarte, com a história dos gabinetes de imprensa da presidência, da Proclamação da República às vésperas do Golpe de 1964.

\section{De Autran a Singer}

A série começa com o escritor Autran Dourado, assessor de Juscelino Kubitschek, quando da inauguração de Brasília. E vai até André Singer, porta-voz e secretário de Imprensa do governo Lula da Silva entre 2003 e 2007. O grande mérito do livro foi se manter fiel às respostas dos entrevistados. O entrevistador agiu como "um facilitador do relato que o entrevistado quisesse fazer", segundo Singer. "Buscou-se sempre preservar a fala original do entrevistado, assumindose que se trata de conteúdo memorialístico, sujeito a falhas e lacunas".

Essa não-intervenção enriqueceu a importância histórica dos relatos. Até porque, em alguns casos, existe a confortável distância no tempo de presidentes falecidos, o que poderia supor uma reflexão crítica mais isenta. Em outros, os ex-presidentes são figuras políticas atuantes na vida pública brasileira, alguns deles controversos e alvo de críticas, como Emílio G. Médici, João Figueiredo, Fernando Collor e José Sarney. Embora não se percebam distorções históricas, a maioria dos entrevistados não deixou de minimizar os erros e maximizar os acertos dos assessorados. São relatos abertos, alguns descontraídos, e que recuperam histórias que poderiam ser perdidas, com o passar do tempo. Daí o valor histórico da edição.

A leitura das entrevistas corrobora aquilo que parece ter sido um consenso de quem acompanha por mais de trinta anos as relações da presidência da República com a imprensa. No período militar, apesar de todos os entraves para o trabalho da imprensa, com censura, prisões, fechamento do Congresso, presidentes que desdenhavam a mídia, um nome se destacou como um dos melhores secretários a passar pelo Planalto: Humberto Barreto, secretário de Imprensa do presidente Geisel. Não era jornalista, mas a intimidade e a confiança do sizudo presidente-militar e o estilo de se relacionar com os jornalistas acabou por consagrá-lo como uma grata surpresa.

Não deixam de transparecer também, de algumas entrevistas, as restrições e dificuldades de relacionamento com o secretário de Comunicação Social do Governo Figueiredo, Said Farhat. Talvez por não ter tido intimidade com o presidente e por ter assumido a secretaria com um projeto mirabolante de tornar 
popular o João, que nunca deixou de ser general e apenas aceitou ser presidente, como uma missão militar, como dizia. Tudo isso talvez tenha contribuído para, de certo modo deixar a impressão de alguém que se preocupou mais em "dotar a Secretaria de Comunicação de uma burocracia superdimensionada, sem necessidade" do que resolver quanto aos problemas de relacionamento entre governo, autoridades e imprensa. Para a Secretaria de Imprensa vale o que se recomenda para tais órgãos: "Estruturas pequenas desse tipo, com gente qualificada, funcionam mil vezes melhor do que organizações pesadas, com pessoal numeroso", diz Carlos Átila, o último porta-voz de Figueiredo.

As entrevistas dos secretários do período militar, de Carlos Chagas a Carlos Átila, desnudam, talvez pela primeira vez, bastidores fundamentais para entender não apenas as relações difíceis dos presidentes com o estamento militar, a imprensa e a sociedade, mas também a dificuldade enfrentada pelos ocupantes dos cargos para desmistificar a instituição imprensa e a imagem dos jornalistas. O papel de Geisel na abertura política sai engrandecido do depoimento de Humberto Barreto. Nada que não se soubesse. Apenas a confirmação da luta de bastidores da linha dura para protelar a abertura. $\mathrm{O}$ mesmo se depreende do dramático relato de Carlos Chagas sobre os últimos dias de Costa e Silva.

As entrevistas repõem algumas versões históricas dos governos no seu devido lugar. Os secretários de imprensa foram testemunhas ou personagens de muitos eventos que entraram para o folclore político do país. Por isso, os depoimentos são importantes para os historiadores, embora alguns não consigam dissimular a admiração, o respeito histórico e a fidelidade política que ainda nutrem pelos presidentes. Isso fica patente em depoimentos que negam o chamado "mensalão", acreditam na predisposição da imprensa contra o governo, asseguram que o impeachment de Collor só aconteceu pela pressão da imprensa, facilitada pelos vazamentos da oposição e pelo temperamento arrogante e autossuficiente do ex-presidente. Enfim, são testemunhos que procuram nos convencer da disposição dos militares para devolver o poder aos civis, o que, convenhamos, só aconteceu pela pressão da sociedade e pelo desgaste da ditadura.

Sobressai dos depoimentos a extrema dependência dos presidentes em relação à Secretaria de Imprensa. Essa área sempre foi considerada difícil e crucial, em qualquer mandato, mesmo para os militares. Por isso, a figura do secretário tornou-se fundamental para os projetos de governo, tanto no período da ditadura, quanto após a abertura política.

Os secretários e porta-vozes eram figuras que cresciam no exercício do poder. Alguns saíram para cargos importantes no Judiciário ou Executivo. Foram decisivos no processo de abertura política, como se depreende dos depoimentos de Carlos Chagas, Antonio Brito, Fernando César Mesquita, Antonio Frota Neto, Carlos Henrique, Francisco Baker, Sérgio Amaral e Ricardo Kotscho.

Os diplomatas no cargo de secretários de imprensa saem consagrados dos relatos, mostrando como rapidamente entenderam o papel da imprensa para a 
presidência da República. Carlos Átila, Pedro L. Rodrigues, Alexandre Parola, Georges Lamazière e Sérgio Amaral são lembrados como hábeis, capacitados e tranquilos para lidar com as autoridades e os jornalistas.

As entrevistas fluem num ritmo muito agradável, porque esclarecem, com detalhes, episódios pouco divulgados ou dos quais só conhecíamos os bastidores. Exemplos como a demissão do ministro Mário Henrique Simonsen do Ministério do Planejamento e a saída do General Golbery, o todo poderoso chefe da Casa Civil no governo Figueiredo, após o atentado do Rio Centro, no Rio de Janeiro. Como Figueiredo cedeu um terreno para a construção do memorial JK, em Brasília, para D. Sarah Kubitschek, apesar das restrições dos militares ao ex-presidente. Assim também para as ações de Geisel impondo-se à corrente militar que resistia à abertura. Ou o episódio da tentativa de expulsar o jornalista Larry Rohter, do The New York Times, que causou desgaste ao governo Lula.

Algumas entrevistas trazem contribuições importantes sobre o papel da imprensa na cobertura da presidência da República, bem como sobre o dever dos governantes em prestar contas das suas atividades. Para os governos que tiveram relações mais conflituosas com a imprensa, como os de Figueiredo, Sarney e Collor, a mídia teria extrapolado seu papel. Carlos Átila admite que "a relação entre jornalistas e governo, pelo menos naquela época, era em grande parte uma relação antagônica”.

\section{0 porta-voz da crise}

A verba de publicidade sempre foi a pedra no sapato dos presidentes e secretários. Todos conheciam o potencial explosivo dessa área. Os secretários de imprensa fugiam dela. Por isso, há um consenso, nas entrevistas, de que assuntos de publicidade deveriam ser separados da Secretaria de Imprensa, como fizeram vários presidentes, entre eles Fernando Henrique e Lula. Antonio Brito dizia que "não tem como funcionar (junto), em primeiro lugar, porque não dá tempo de fazer as duas coisas; em segundo lugar, porque é um perigo misturar". Que essa área é complicada, souberam muito bem Collor e Lula. Um dos primeiros auxiliares a cair fora na crise que desaguou no impeachment foi o assessor de publicidade de Collor. E Lula amargou poucas e boas com companheiros do partido e publicitários numa relação nada republicana, no "escândalo do mensalão". "Em democracias plenas, os governos não devem gastar dinheiro para dizer que são bons governos”, diz Pedro Luiz Rodrigues, que trabalhou curto período no fim do governo Collor.

Antonio Brito conta os momentos da internação do presidente Tancredo Neves, o drama que viveu assumindo um cargo no meio de uma crise. Usou sua experiência de repórter para traduzir dia a dia o que acontecia com o presidente, principalmente pela onda de boatos que invadiu o país naquele período. Brito revela até mesmo os bastidores de uma controvertida foto feita no Hos- 
pital de Base de Brasília, com Tancredo e a equipe médica. "A tentativa foi de, em circunstâncias imprevistas e dramáticas, tentar agir com profissionalismo e dignidade". Até porque, como disse Toninho Drummond, secretário de imprensa de Sarney por quatro meses, "a imprensa é muito superficial. Não sabe $70 \%$ do que realmente ocorre no dia a dia de um governo". Brito reconhece que ter sido a ponte, naquele difícil período, entre a versão oficial dos fatos e a população, lhe deu grande popularidade.

Os porta-vozes de Sarney (1985-1990) contam a resistência da mídia ao presidente-tampão, que herdou o cargo com a morte de Tancredo. Apesar da experiência e da cordialidade do presidente, foi muito difícil a relação com a imprensa, o que de certo modo teria facilitado a ascensão de Collor, que vivia batendo em Sarney. Da popularidade angariada com o Plano Cruzado ao caos de uma inflação galopante e à pressão de dez mil greves no período, os secretários do governo Sarney narram os momentos difíceis para vencer os cinco anos de mandato. Ou seja, o fato de Sarney ser jornalista e ter experiência de comunicação não o ajudou muito.

Qual seria o perfil ideal para secretário de imprensa? Para Fernando C. Mesquita, uma "pessoa discreta, ter conhecimento, muita paciência para ouvir, guardar as emoções”. Para Carlos Henrique, que também trabalhou com Sarney, "requer passado, uma história que lhe forneça essa colheita [...] e, claro, a confiança do presidente". "Tem que ser um jornalista”, diz Frota Neto. Para Ricardo Kotscho, o secretário é "um amortecedor de crises, para evitar que elas aconteçam, utilizando as informações de que dispõe”.

Para Etevaldo Dias, secretário de imprensa no fim do governo Collor, o papel desse profissional, num período de crise, é "não insuflar o presidente contra a mídia. Agir como mediador". Mas, reconhece, uma "assessoria de imprensa ajuda, mas não salva um governo". Francisco Baker, secretário de imprensa de Itamar Franco, admite que "não adianta querer brigar com um órgão de imprensa, se tem prestígio, circulação".

Talvez nada resuma melhor a importância dessa difícil relação do que as palavras de Ricardo Kotscho, secretário de imprensa de Lula, que acabou saindo após dois anos de pressões: "A última palavra é da imprensa. Você quer brigar, brigue, mas nós vamos perder".

No Planalto, com a imprensa vale como contribuição não apenas à história política do país, recuperando acontecimentos decisivos para compreensão do Brasil dos últimos sessenta anos ou pela clareza com que aborda relações até agora restritas a um pequeno grupo que compartilhava o poder. Mas também como guia para estudantes, jornalistas, assessores de imprensa e professores entenderem melhor as dificuldades de conciliar interesses políticos e conchavos palacianos com o direito de informar. 